Article

\title{
Reduced Vision with Erythrocyte G6PD Enzyme Status Among The School Children of Dhaka City
}

\author{
Ayesha Yasmin ${ }^{1}$, Nasim Jahan ${ }^{2}$, Rezina Akter ${ }^{3}$
}

\begin{abstract}
Background: Globally more than 123 million people have impaired visual status due to reduced vision (visual acuity $<6 / 6 \mathrm{~m}$ ) and many of them results into complete or partial blindness. The situation is more crucial in case of children whose reduced vision is usually remain undetected. Apparently healthy children with reduced vision may also found with asymptomatic erythrocyte G6PD enzyme deficiency. Objective: This study has been designed to detect the presence of reduced vision among apparently healthy school children of Dhaka city and also to measure their erythrocyte G6PD enzyme level. Method: This cross sectional study was carried out in the Department of Physiology, Sir Salimullah Medical College (SSMC) during the period of 2007-2008. For this purpose 500 children irrespective of sex and aged 6 to 12 years was selected as study population from different schools of Dhaka city. Children were grouped according to their visual status using Snellen's letter chart (1862). Erythrocyte G6PD enzyme was measured by Spectrophotometric method. Children with normal visual acuity $(6 / 6 \mathrm{~m})$ were grouped as group- A (control) and those with reduced visual acuity $(<6 / 6 \mathrm{~m})$ were in group B. Erythrocyte G6PD enzyme level was measured and compared between the groups. Results: Statistically significant $(p<0.05)$ number of children (12.8\%) were detected to have reduced vision when compared with that of normal vision. Reduced vision was present in most of the male children \& it was bilateral type of reduced vision. Mean erythrocyte G6PD enzyme level was almost similar in both groups and no significant ( $>>0.05)$ difference was observed when compared between them. Conclusion: This study revealed that reduced vision may present in apparently healthy children. So, earlier detection of reduced vision can help to minimize the visual complications in childhood age. This study also revealed that there is no association between reduced vision and G6PD enzyme deficiency.
\end{abstract}

Key words: Reduced vision, G6PD deficiency, Visual acuity

J Bangladesh Soc Physiol. 2011 June; 6(1): 64-69 For author affiliations, see end of text.

http://www.banglajol.info/index.php/JBSP

\section{Introduction:}

$\mathbf{U}$ ndetected reduced vision in childhood is one of the common sufferings of our population. The term 'reduced vision' means visual acuity less than $6 / 6 \mathrm{~m}$ which can not be fully corrected by lenses ${ }^{1}$. Uncorrected refractive errors including myopia, hypermetropia and astigmatism are the usual causes of reduced vision ${ }^{2}$. Furthermore, progressive painless reduced vision in children can also be developed from- growing cataract, juvenile glaucoma, optic atrophy, hereditary macular degeneration etc. ${ }^{1-3}$ Transmission of reduced vision is generally genetical and may also be present with other genetic disorders like ocular albinism and achromatopsia ${ }^{3}$.

Many studies have been conducted world wide including our country to determine the 
prevalence of reduced vision ${ }^{4-10}$. It has been observed that about 12.8 million people of 5 to 15 years age have been suffering from reduced vision with the highest prevalence reported in the urban and highly developed urban areas of south-east Asia and China ${ }^{4}$. The total percentage of reduced vision was found in about 5.65\% among the school children of Dhaka ${ }^{5}$. It is reported that $17.1 \%$ of children have reduced vision among 4,634 study population residing in the suburban area near Kualulampur city ${ }^{6}$. Comparatively higher percentage of reduced vision were observed in urban school children ${ }^{7-}$ ${ }^{10}$. Whereas, lower percentage of reduced vision have also been reported among the children of similar age group from rural areas of Bangladesh and other countries ${ }^{11-13}$.

Undetected reduced vision can create many hazards in daily life. Several professions likedriving , armed forces, navigation, pilot require normal visual acuity. In our country large number of children with reduced vision remain undetected and neglected. It greatly affects their class performance as well as hamper their daily routine work. Moreover, if the condition left uncorrected it can progress into complete or partial blindness ${ }^{9-15}$.

Glucose-6-Phosphate Dehydrogenase enzyme deficiency is an $\mathrm{X}$-linked recessive disorder and there are more than 200 structural variants of G6PD $^{16-18}$. The gene for Glucose-6-phosphate Dehydrogenase is localized to Xq 28 chromosome ${ }^{16}$.G6PD enzyme deficiency is widely disseminated throughout Africa, the Mediterranean basin, Middle East, South East Asia and indigenous populations of the Indian subcontinent ${ }^{17}$. The prevalence of G6PD deficiency in South East Asian countries are $3-6.9 \%$ among the males ${ }^{17}$. Usually, most of the G6PD variants are harmless and are not associated with any clinical or hematological abnormalities ${ }^{16-19}$.

However, few research works reported about the presence of reduced vision associated with Glucose-6-Phosphate Dehydrogenase (G6PD)

J Bangladesh Soc Physiol. 2011 June; 6(1): 64-69 enzyme deficiency 20,21 . A study among Sardanian population of Italy showed 5\% patients with G6PD enzyme deficiency had visual defect $^{21}$. Whereas, another group of researchers reported presence of G6PD enzyme deficiency among children without any defective visual acuity ${ }^{22}$.

Reduced vision along with G6PD enzyme deficiency can be present in apparently healthy children as both the diseases are transmitted genetically $^{3,16-22}$. Some studies have been done on this aspect in abroad. But, little is known about presence of reduced vision along with erythrocyte G6PD enzyme deficiency in our country.

Considering all these aspects present study was designed to find out the visual status by detecting the presence of reduced vision among the apparently healthy school children of Dhaka city and their erythrocyte G6PD enzyme level was also measured to find out any association.

\section{Methods}

This cross sectional study was carried out in the Department of Physiology, Sir Salimullah Medical College, Mitford, Dhaka, during the period between July 2007 to June 2008. For this purpose, five hundred (500) apparently healthy middle class school children aged 6 to 12 years irrespective of gender, race and religions were selected as study population from four different schools of old Dhaka city. Children using medicine on eyes, having any infection and any other ocular problems were excluded from the study. The study populations were grouped according to their visual status into group A (control group) consisted of children with normal vision and group B (experimental group) consisted of children with reduced vision (visual acuity $<6$ / $6 \mathrm{~m}$ ). Group B was further divided into subgroups as- group a, b, c, d and e according to their level of visual acuity. Before starting the examination, objectives, risks and benefits of the study procedure were briefly described and informed 


\section{Article}

consent was taken from each of the parents/legal guardians. Permission from Institutional ethics committee (IEC) of SSMC and respective school authorities were also taken. Information concerning visual status of the study population was recorded and sociodemographic information was collected from administrative questionnaire. The test for visual acuity was done with Snellen's (Snellen 1862) letter chart by standard method \& reduced vision was detected. Each eye was tested separately and together. Subject wearing glass was asked to read by naked eye then the test was repeated on each eye with glasses. According to Snellen's letter chart visual acuity less than $6 / 6 \mathrm{~m}$ or $20 / 20 \mathrm{ft}$ was considered as reduced vision. The result was expressed as meters. Under aseptic procedure, $0.2 \mathrm{ml}$ of venous blood was collected from the subjects for the measurement of G6PD enzyme. After collection, the sample of blood was washed with $02 \mathrm{ml}$ of $0.9 \% \mathrm{NaCl}$ solution and centrifuged at a rate of 300 rpm for 3 times. Erythrocyte G6PD enzyme level was measured by Spectro photometric method (Randox) in the Department of Biochemistry, Armed Forces Institute of Pathology, CMH, Dhaka. According to this method normal range of G6PD enzyme level is $245-299 \mathrm{mU} / 10^{9}$ erythrocytes. The measurement was done in all the children of group B as well as 64 randomly selected children from group A. The results were compared between the groups and data was statistically analyzed by Student's t test (unpaired) and $\chi^{2}$ test using computer based SPSS.

\section{Results}

Visual status of the study population shows that the percentage of group B (12.8\%) was comparatively lower than that of control group A $(87.2 \%) \&$ the difference was statistically significant $(\mathrm{p}<0.05)$ (Figure-1).

Percentage of subjects with different visual acuity in different groups and subgroups showed that maximum percentage of subjects was in sub group
Reduced Vision with Erythrocyte G6PD

c (6/18m) in comparison to that of group A and the difference was statistically significant $(\mathrm{p}<0.05)$. However, no statistical significant $(\mathrm{p}>0.05)$ difference was observed among the other subgroups of group B when compared to that of group A (Table I).

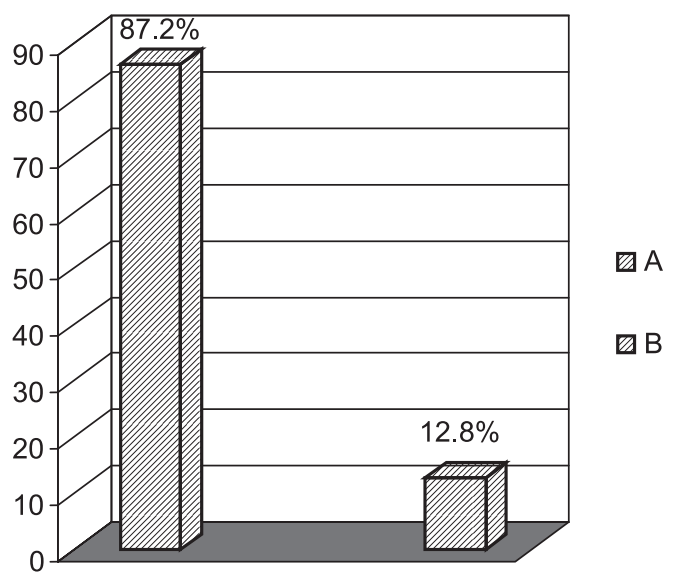

Figure 1: Visual status among study population

Table I: Distribution and comparison of sub groups (of Group B) with control (Group A) ( $\mathrm{n}=500$ ).

\begin{tabular}{|c|c|c|c|}
\hline Groups & $\begin{array}{c}\text { Number } \\
\text { (n) }\end{array}$ & $\begin{array}{c}\text { Percentage } \\
(\%)\end{array}$ & $\begin{array}{c}\text { Visual } \\
\text { acuity (m) }\end{array}$ \\
\hline A (Control) & 436 & $(87.02)$ & $6 / 6$ \\
\hline B (Experimental) & 64 & $(12.8)$ & \\
\hline $\mathrm{a}$ & 05 & (1.0) & $6 / 9$ \\
\hline b & 15 & (3.0) & $6 / 12$ \\
\hline C & 25 & (5.0) & $6 / 18$ \\
\hline d & 17 & (3.4) & $6 / 24$ \\
\hline e & 02 & $(0.4)$ & $6 / 36$ \\
\hline \multicolumn{4}{|l|}{ Statistical analysis } \\
\hline & \multicolumn{3}{|c|}{ p Value } \\
\hline A vs a & \multicolumn{3}{|c|}{1} \\
\hline A vs b & \multicolumn{3}{|c|}{0.1} \\
\hline A vs $c$ & \multicolumn{3}{|c|}{$0.05^{*}$} \\
\hline A vs $d$ & \multicolumn{3}{|c|}{0.1} \\
\hline A vs e & \multicolumn{3}{|c|}{1} \\
\hline
\end{tabular}

Results are expressed in number and percentage. As test of significance Chi-Square $\left(\chi^{2}\right)$ test was performed.

J Bangladesh Soc Physiol. 2011 June; 6(1): 64-69 
The children of subdivisions of group B was further analyzed according to their sex and type of reduced vision. The percentage of female participants were less in number. The percentage of subjects with unilateral type of reduced vision was lower than that of bilateral type and the difference was not statistically significant ( $>>0.05$ ) (Table II).

Mean G6PDenzymelevel of group B $( \pm 245)$ was almost similar to that of group A $( \pm 249)$ and no statistically significant $(p>0.05)$ difference of this value was observed between the two groups (Table III, IV).

Table II: Distribution of the subgroups (of group B) by sex and types of reduced vision whether unilateral or bilateral $(\mathrm{n}=64)$.

\begin{tabular}{lccccccc}
\hline Groups & \multicolumn{9}{c}{ Male } & \multicolumn{2}{c}{ Female } & Number & $(\%)$ & \\
& & $\mathrm{n}$ & Number & $(\%)$ & & & \\
\hline B & 64 & & & 2 & $(3.12)$ & \\
& $\mathrm{a}$ & 5 & 3 & $(4.68)$ & 6 & $(10.93)$ & $0.622^{\text {ns }}$ \\
& $\mathrm{b}$ & 15 & 9 & $(12.5)$ & 11 & $(17.18)$ & \\
& $\mathrm{c}$ & 25 & 14 & $(21.87)$ & 9 & $(14.06)$ & \\
& $\mathrm{d}$ & 17 & 8 & $(12.5)$ & $(3.12)$ & & \\
e & 02 & nil & 2 & &
\end{tabular}

Distribution and Statistical analysis

\begin{tabular}{|c|c|c|c|c|c|}
\hline \multirow[t]{3}{*}{ Sub groups } & \multicolumn{4}{|c|}{ Type of reduced vision } & \multirow{3}{*}{$\mathrm{p}$} \\
\hline & $\begin{array}{r}\text { Unilateral } \\
\text { number (\% }\end{array}$ & $\frac{\text { Bilateral }}{\text { humber (\%) }}$ & $\frac{\text { Unilateral }}{\text { number (\%) }}$ & $\frac{\text { Bilateral }}{\text { number (\%) }}$ & \\
\hline & \multicolumn{2}{|c|}{ Male } & \multicolumn{2}{|c|}{ Female } & \\
\hline $\mathrm{a}$ & $1(1.5)$ & $2(3.1)$ & $1(1.5)$ & $1(1.5)$ & \\
\hline $\mathrm{b}$ & $3(4.6)$ & $6(9.3)$ & $3(4.6)$ & $3(4.6)$ & \\
\hline $\mathrm{c}$ & $6(9.3)$ & $8(12.5)$ & $5(7.8)$ & $6(9.3)$ & $0.874^{\mathrm{ns}}$ \\
\hline $\mathrm{d}$ & $2(3.1)$ & $6(9.3)$ & $5(7.8)$ & $4(6.2)$ & \\
\hline e & 0 & 0 & 0 & $2(3.1)$ & \\
\hline
\end{tabular}

Results are expressed as number and percentage (\%).Chi-square $\left(\chi^{2}\right)$ test was performed as test of significance. ns $=$ Not significant .

Table: III Erythrocyte G6PD enzyme status among the groups $(\mathrm{n}=128)$.

\begin{tabular}{ccc}
\hline Groups & Number & $\begin{array}{c}\text { mean G6PD mU/ } \\
10^{9} \text { erythrocytes }\end{array}$ \\
\hline A & 436 & 249 \\
B & 64 & 245 \\
a & 05 & 246 \\
b & 15 & 247 \\
C & 25 & 245 \\
d & 17 & 245 \\
e & 02 & 244 \\
\hline
\end{tabular}

Group A: control (normal vision). Group B: Experimental (reduced vision).

\section{Discussion}

In present study the percentage of subjects with reduced vision among the school children of Dhaka city was $12.8 \%$. Finding of the present study is similar with the other studies done in home $^{5}$ and abroad ${ }^{6-10}$. However, the result is not in agreement to those of other researchers ${ }^{11-13}$ who reported that lower percentage of reduced vision was present among the children of similar age group. This discrepancy may be due to selection of their study sample from rural areas only.

Reduced vision was present in both sexes of present study population, but most of them were 
male. However, the difference of percentage between male \& female was statistically not significant ( $p>0.05$ ). The finding is in consistent to those of other workers ${ }^{10}$. On the contrary, it is not in agreement to those of other researchers ${ }^{6,13}$ who reported an increased prevalence of reduced vision among the female children of similar age group. This dissimilarity might be due to maximum number of female participants in their study population.

Present study also revealed that most of the children had bilateral type of reduced vision. The study done by Trivedi et al.(2006) ${ }^{7}$ also showed similar findings. However, several researchers ${ }^{13}$ had demonstrated unilateral type of reduced vision. This dissimilarity might be due to genetic inheritance ${ }^{7}$.

Erythrocyte G6PD enzyme level among the children with reduced vision was almost similar to that of children with normal vision. Though one child with reduced vision had G6PD enzyme deficiency but it was mild. Statistically no significant difference was observed when compared between the groups. The finding is similar to the observation of Antonio Pinna etal.(2008) ${ }^{21 .}$ However, few research work showed dissimilar findings ${ }^{22}$.

Uncorrected refractive error was found to be the main cause of reduced vision among the study population of present series as no other cause was detected. It is supported by a number of other researchers $^{5-13}$. The possible reason of reduced vision might be excessive near work of vision such as short distance reading, excessive close watching of television and use of computers, playing video games, study under insufficient lights etc ${ }^{1,2,4}$. Increased number of children with reduced vision might also be the consequences of unawareness as well as negligence of the parents and teachers about their children's visual status.

Several studies ${ }^{4,14,15}$ suggested that poverty and malnutrition are the major causes of reduced vision in developing countries. But in present study no such impact of socioeconomic condition was found among the children with reduced vision along because all the children in this study were from same middle socioeconomic class. The finding is again in consistent to those of other researchers ${ }^{10,21,22}$.

Erythrocyte with G6PD enzyme deficiency was observed in a number of children with reduced vision (1.5\%) without any symptoms. However, none of the children with normal vision had G6PD enzyme deficiency. As erythrocyte G6PD enzyme deficiency is common in males in this subcontinent ${ }^{16,17}$ the cause might be genitical as no other causes were revealed. However, this observation needs further confirmation.

\section{Conclusion}

Therefore, this study revealed that reduced vision is not uncommon in apparently healthy school children of urban population. Again, there is no association between reduced vision and G6PD enzyme deficiency. Although further research works on screening of visual status including their causes and correction with a larger sample size among the apparently healthy children in rural and urban populations should be carried out. Appropriate measures should be recommended for the affected population for their better living.

\section{Acknowledgement}

The authors are grateful to the participated children, parents and respective school authorities for their voluntary participation and cooperation. We are also thankful to $\mathrm{CMH}$ for providing lab facilities. We are acknowledged to the Director of Medical Education for extending financial support.

\section{Author affiliations}

1. Ayesha Yasmin, Associate Professor, Physiology, Enam Medical Collge

2. Nasim Jahan, Professor \& Head, Department of Physiology, Sir Salimullah Medical Colege, Dhaka. Email: prof.dr.nasimjahan@yahoo.com

3. Rezina Akter, Associate Professor, Department of Physiology, Sir Salimullah Medical College, Dhaka. E-mail: akter.rezina@yahoo.com

J Bangladesh Soc Physiol. 2011 June; 6(1): 64-69 


\section{References}

1. Stephen J A, Ramanjit and Tandon Radhika (eds). Colour vision and Diminution of vision. In: Parson's Diseases of the Eye. Reed Elsevier, 2007, p 269-270 and 91-100.

2. Vitale S, Cotch M F, Sperduto R D. Prevalence of visual impairment In United States. JAMA. 2006; 295: 2158- 2163.

3. Cyril A Keele, Eric Neil and Norman Joels. Cone and Colour Vision and Visual acuity. In : Samson Wright's Applied Physiology, $13^{\text {th }}$ ed. Oxford Medical Publications, India, 2000, p 383-385 and 380.

4. Reskinoff Serge, Pascolini Donatella, Silvio P, Gopal P. Global magnitude for visual impairment caused by uncorrected refractive errors in 2004 . Bull World Health Organ. 2008; 86 (1): 1-13.

5. Hossain Anwar. Study on pattern of refractive error in Bangladesh and their management in clinical study on 500 cases. BSMMU. 1989; 1-108.

6. Pik- Pin Goh, Abqariyah Yahya, Gopal $P$ and Leon B Ellwein. Refractive error and visual impairment in School age children in Gombak. Ophthalmology. 2005; 112 (4) : 678-685.

7. Trivedi Vivek, Zalawadiya Sandip, Janardan V, Pawar Tapaswi, Kupmavat Bhavana. Prevalence of refractive error In children (Age group 7 to 15 years) of rural and urban Areas of Gujarat : A population based study, 2006.

8. Eugenio Maul, Barroso Silviana, Sergio R. Munoz, Robert D. and Leon B. Refractive error study in children: results from La Florida, Chile. American Journal of Ophthalmology. 2000. 129 (4): 445- 454.

9. Ikram M. Hamayun, Cheema Tasneem, Farooq Iftikhar, Chaudhry Aamir, Ayesha, Saadia, Umber, Attiya, Ijaz, Mir M. and Umbreen. Colorblindness and Visual acuteness; Incidence in rural and urban population at Faisalabad. The Professional. 2000; 03:1-3.

10. Kalikivayi V, Naduvilath T J, Bansal A K, Dandona L. VisualImpairment in school children in Southern India. Community Eye Care. 1997. 45 (2): 129-134.

11. Raihan Abu, Rahmatullah Salahuddin, Hasan M. Arefin and Banu Tahamina. Prevalence of significant refractive error, low vision and blindness among children in Bangladesh. 2005;1282: 433-437.

12. Gopal P Pokharel, A Dominique Negrel, Sergio $\mathrm{R}$ Munoz and Leon B Ellwein. Refractive error study in children: results from Mechi Zone, Nepal. American Journal of Ophthalmology. 2000; 129 (4): 436-444.

13. Jialiang Zhao, Xiangjun Pan, Ruifang Sui, Sergio R Munoz, Robert S. and Leon B. Refractive error study in Children : results from Shunyi District China. American Journal of Ophthalmology. 2000; 129 (4): 427- 235.

14. Dineen B P, Bourne R R A, Ali S M, Huq D M and Johnson J. Prevalence and causes of blindness and visual impairment In Bangladeshi adults: Results of the National Blindness and Low vision survey of Bangladesh. Br J Ophthalmol. 2003. 87 (7): 820-828.

15. Bruce I, McKennel A, Walker E. Blindness and Partially sighted Adults Britain. The Royal National Institute of the Blind (RNIB) Survey.1991.

16. Kumar Parvin and Michael Clark. Glucose 6 Phosphate Dehydrogenase Deficiency.In: Kumar and Clark clinical medicine. $5^{\text {th }}$ ed. W. B. Saunders, 2002, p 433-438.

17. Victor A Hoffbrand, Catovosky Daniel and Edward GD. Glucose-6- Phosphate Dehydrogenase Deficiency. In: Postgraduate Haematology, $5^{\text {th }}$ ed. Blackwell Publishing; 2005.

18. Firkin F, Chesterman, C., Penington, D. and Rush B. G6PD Variants.In: de Gruchey's clinical hematology in medical practice. $5^{\text {th }}$ ed. Blackwell Science, Berlin; 1989.

19. Filosa S, Calabro V, Lania G, Vullami T J, Brancati C, Tagaralli A, Luzzato L, Martini G. G6PD haplotypes spanning Xq28 from F8C to red green colour vision. Genomics. 1993; 17(1): 6-14.

20. Wu LZ, Zeng LH, Ma QY, Xie YJ, Chen YZ and Wu DZ. Hereditery characteristics of enzyme deficiency and dermatoglyphics in congenital colour blindness. Jpn J ophthalmol. 1988; 32 (2): 236-245.

21. Antonio Pinna, Giuliana Solinas, Carlo Masia, Angelo Zinellu, Ciriaco Carru, and Arturo Carta Glucose 6 Phosphate Dehydrogenase (G6PD) deficiency in nonarteritic anterior ischemic optic neuropathy in a Sardanian population, Italy. Invest Ophthalmol Vis Sci. 2008;49:1328-1332.

22. Urmi V, Sarvanan N, Rajiv K \& Khalfan AlHadrami. Refractive error \& visual functions in children with special needs compared with first grade students of Oman. Middle East journal of Ophthalmology. 2010; 17 (4) : 297- 302. 